\title{
State of Human Development: SAARC and Nepal
}

\author{
Homa Nath Poudel*
}

\begin{abstract}
Human Development Index (HDI) is the strongest and widely used measure of overall performance of countries. The '2014 Human Development Report - Sustaining Human Progress: Reducing Vulnerabilities and Building Resilience' provides a fresh perspective on vulnerability and proposes ways to strengthen resilience. It highlights the need for both promoting people's choices and protecting human development achievements. It takes the view that vulnerability threatens human development and, unless it is systematically addressed, progress will be neither equitable nor sustainable. Based on the light of this recent report launched on 24 July, 2014, here in this study, an attempt has been made to global highlights of the report, comparison of SAARC countries and remarks on the status of Nepal.
\end{abstract}

Key Words: Human development index, SAARC, rank, value, highlights.

\section{BACKGROUND}

Human Development Index (HDI) is the comparative measure of life expectancy, literacy and income for living standard and overall performance of countries worldwide. The 2014 HDI report covers 187 countries, the same number as in 2013 and 2012. The HDI emphasizes that people and their capabilities should be the ultimate criteria for assessing the development of a country, not economic growth alone. The HDI can also be used to make national policy choices, asking how two countries with the same level of GNI per capita can end up with different human development outcomes.

There have been significant revisions of the methodology for computation of the HDI. The modifications in methodology include the change in maxima for normalization of dimensional indices - previously they were equal to the observed maxima over the period since 1980, now they are fixed at 85 for life expectancy (LE), 15 years for mean years of schooling (MYS), 18 years for expected years of schooling (EYS), and \$75,000 for GNI per capita (GNI pc). The previously used approach of 'observed maxima' was criticized mainly on the grounds that the HDI of the country should depend only on the country's own achievements, however when using the observed maxima the HDI also depended on other countries, on those whose values were used as maxima. The other change is in the way the education indicators are aggregated. Previously used geometric aggregation was criticized on the grounds that a typical developing country has a (much) higher

* Mr. Poudel is Lecturer of Economics Education, Prithvi Narayan Campus, T.U., Pokhara 
value of expected years of schooling than of mean years of schooling. By aggregating these two indicators with the geometric mean such a country is 'penalized' because of the difference, although the country is improving education level by having more children attending school at all levels. The use of the arithmetic mean provides an equal treatment to both indicators. These changes have a minimal impact on values and ranks.

Although the HDI is calculated with the larger number of decimals, only three are reported. Often there are ties in the HDI values, which is also reflected in ties in the ranks. The HDI values, by the very nature of the estimated components, are not significant beyond three decimal places.

The concept of human development is much broader than what can be captured in the HDI, or any other of the composite indices in the Human Development Report -Inequality-adjusted HDI, Gender Inequality Index and Multidimensional Poverty Index (Nepal, 2056:64-65). The HDI, for example, does not reflect political participation or gender inequalities. The HDI and the other composite indices can only offer a broad proxy on some of the key issues of human development, gender disparity and human poverty.

UNDP publishes the HDI report of all the member countries of UN individually, and continentwise, region-wise and group wise as well. South Asian Association for Regional Co-operation is one of such group. SAARC was established in 1985 with a broad objective of promoting the welfare of the people of South Asia through regional co-operation. Bangladesh, Bhutan, India, Maldives, Nepal, Pakistan and Sri-Lanka are the founder members of the organization from its establishment. The number of member states reaches eight when Afghanistan joined it in 2007. Hence the analysis of HDI for all SAARC countries has been done for three years in the interval of two years i.e. 2010, 2012 and 2014. Most of the analysis is based on the single report entitled Human Development Report. Efforts have been made to compare the position (rank) of individual country in SAARC and total/ average annual rate of change for this period selected for the study. Besides, it has also been tried to ascertain in which group a particular country falls.

\section{DATA AND METHODS}

The methodology of this present study is a good blend of qualitative and quantitative approach. The study makes use of only secondary data. As it was not possible to personally collect the data, the data were collected from the UNDP Human Development Report 2014. The sample consists of SAARC countries. The data were analyzed through MS Excel. Some statistical tools such as percentage, mean were used in data analysis along with qualitative description. The scope of the study is narrowed down to SARRC countries only.

\section{PRESENTATION AND ANALYSIS}

The report '2014 Human Development Report - Sustaining Human Progress: Reducing Vulnerabilities and Building Resilience' offers a fresh perspective on what makes people vulnerable, and proposes ways to strengthen resilience. The report introduces the idea of life cycle vulnerabilities, which arise from sensitive points in life where shocks can have greater impact. It stresses the importance of the first 1,000 days of life, and of the transitions from school to work, 
and from work to retirement. The report urges governments to commit to the universal provision of basic social services and social protection to build resilience, especially for the poor and other vulnerable groups. It argues that countries in Asia and the Pacific do not have to wait to become rich in order to provide adequate social protection or basic social services. Staggering rates of poverty, high inequality and frequent natural disasters and crises threaten the progress of human development in Asia and the Pacific. Addressing these challenges requires a host of initiatives, including universal provision of social services and a strong system of social security benefits. Across Asia and the Pacific, over a billion people live just above the extreme poverty line, on more than US $\$ 1.25$ but less than US $\$ 2.50$ a day. The report asserts that those who face multiple deprivations are especially at risk of falling back into poverty if a disaster or crisis occurs (UNDP, 2014).

Making the case that cohesive societies work better, the report calls for strong social protections such as pensions and unemployment insurance for countries at all stages of development. The report also highlights that a lack of decent, well paid jobs - especially for youth - is a major challenge in Asia and the Pacific. In many countries of the region, youth unemployment is relatively high: 23 percent in Iran, 22 percent in Indonesia, 17 percent in Sri Lanka, 16 percent in Philippines and Samoa and 14 percent in Timor-Leste. The report urges governments to fast-track education reform policies and to accelerate broad-based economic growth to create decent and well paid jobs that are essential to improving living standards. In addition, food insecurity, violence against women, and civil conflict and disaster risks (such as landslides and rising sea levels) linked to climate change further threaten the security of millions of people. It is hoped that by addressing vulnerabilities, all people may share in development progress, and human development will become increasingly equitable and sustainable.

The findings of the report show that more than 2.2 billion people are either near or living in multidimensional poverty - that is exhibiting several factors that constitute deprivation such as poor health, lack of education, inadequate living standard, lack of income, disempowerment, poor quality of work and threat from violence. Nearly $80 \%$ of the global population lack social protection, while $12 \%$ (842 million people) suffer from chronic hunger - and nearly half of all workers across the world are in informal or precarious employment. Youth unemployment is a growing problem for developing countries, particularly as more young people go to school. When people are more educated, their relationship with citizenship changes, and they expect more from jobs. Another finding was the effect of globalization on economic vulnerability. Globalization has brought countries together and provided more opportunities, but it has also increased the risk of adverse events, like the recession, being transmitted more rapidly.

About East Asia and the Pacific, the report shows that there are six countries in the high human development group from the region, 11 in the medium and three in the low human development group. The average HDI value for the region is 0.703 , slightly above the world average of 0.702 . Similarly, south Asian highlights show that there is no country in the very high human development group from the region. The average HDI value for the region, at 0.588 , is below the world average of 0.702 (UNDP, 2014). 
The report has not shown any sea-change for SAARC countries. The HDI status of SAARC countries has been presented in Table 1 mention below:

Table 1: HDI Ranks and Values of SAARC Countries

\begin{tabular}{|c|c|c|c|c|c|}
\hline \multicolumn{3}{|c|}{4 Highest HDIs } & \multicolumn{3}{|c|}{4 Lowest HDIs } \\
\hline Rank & Country & HDI & Rank & Country & HDI \\
\hline \multicolumn{3}{|c|}{ High human development } & \multicolumn{3}{|c|}{ Low human development } \\
\hline 1 & Sri Lanka & 0.750 & 1 & Afghanistan & 0.468 \\
\hline \multicolumn{3}{|c|}{ Medium human development } & 2 & Pakistan & 0.537 \\
\hline 2 & Maldives & 0.698 & 3 & Nepal & 0.540 \\
\hline 3 & India & 0.586 & \multicolumn{3}{|c|}{ Medium human development } \\
\hline 4 & Bhutan & 0.584 & 4 & Bangladesh & 0.558 \\
\hline
\end{tabular}

Source: UNDP, Human Development Report 2014.

The report shows that Nepal climbed up 12 places to $145^{\text {th }}$ among 187 countries from life expectancy, education levels and incomes. Nepal is sixth among the SAARC countries. Sri Lanka leads the SAARC countries at $73^{\text {rd }}$, followed by Maldives (103), India (135), Bhutan (136), Bangladesh (142), Pakistan (146) and Afghanistan (169). Pakistan was above the states of Nepal last year. The report has put inequality adjusted HDI of Nepal at 0.588 points stating that income inequality is rising continuously while there is prevalence of disparity even in education. Nepal has 0.384 points in IHDI with the gap due to inequalities for income at 27.8 percent, life expectancy 21.1 percent and education 44 percent. The report states that 63.2 percent of male is above 15 of years working age while the corresponding figure for women is 54.3 percent. Similarly, 17.9 percent of women have received education beyond the school level, while it is 39.9 percent for men. Representation of women in the parliament is 33.2 percent. It has put the proportion of Nepalis with daily income of less than US\$1.25 from 2002 to 2012 at 24.82 percent while the national figure for people under the poverty line in 25.2 percent. The multidimensional poverty rate is 18.1 percent and extreme poverty is 19.6 percent (as cited in www.gorkhapatra.org.np).

Nepal leads the least development countries (LDC) with 0.540 overall points. It was 0.526 points last year. Overall point near to one is considered good. The report has classified 49 countries as those with very high, 53 with high, 42 with medium and 43 with low human development. It has put average life expectancy of Nepalis at 68.4 years. Nepalis are admitted at a school at an average age of 3.20 years and spend 12.40 years at school on an average. It has put the per capita national income at US\$2,194. Norway and Australia are in top two once again while the USA has fallen from third to fifth in HDI. Niger retains the bottom place even this year. Following table shows the HDI value of SAARC countries in three selected years for the study. 
Table 2: Trends of Human Development Index in SAARC Region, 2010-2014

\begin{tabular}{lccc}
\hline SAARC Countries & \multicolumn{3}{c}{ Human Development Index } \\
\cline { 2 - 4 } & 2010 & 2012 & 2014 \\
\hline Afghanistan & 0.349 & 0.374 & 0.468 \\
Bangladesh & 0.469 & 0.515 & 0.558 \\
Bhutan & $0.482^{*}$ & 0.538 & 0.584 \\
India & 0.519 & 0.554 & 0.586 \\
Maldives & 0.602 & 0.688 & 0.698 \\
Nepal & 0.428 & 0.463 & 0.540 \\
Pakistan & 0.490 & 0.515 & 0.537 \\
Sri Lanka & 0.658 & 0.715 & 0.750
\end{tabular}

Source: UNDP, Human Development Report 2010, 2012, 2014.

Note: *The HDI of Bhutan for the year 2010 has been readjusted as per the measures used to compute HDI in 2010.

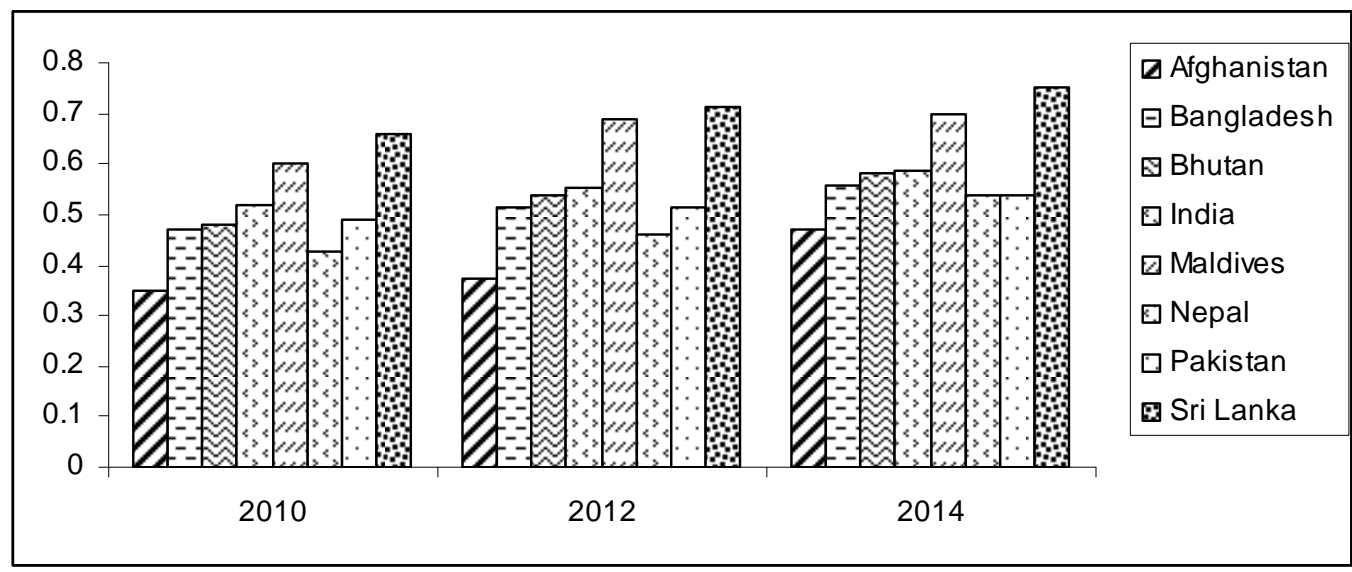

Fig. 1: HDI Value of SAARC Countries

The above table depicts that all eight countries of SAARC have shown comparative and continuous progress in HDI in three years selected for the study i.e. 2010, 2012 and 2014. Amongst SAARC countries Sri-Lanka is at the top and Afghanistan has lowest value in all those years. To concentrate in 2014, Sri-Lanka is leading SAARC countries being in $73^{\text {rd }}$ position with the HDI value 0.750 whereas Afghanistan has been continuing its history of being lowest in SAARC with HDI value 0.468 positioned in $169^{\text {th }}$ rank in global spectrum among 187 countries included in the formal report. Nepal with tiny progress stands at the top of the countries of low human development index. The rank of Nepal is constant in 2014 i.e. 145 but the value has slightly increased which is not capable to alter the rank. It was 0.428 in 2010 , reached 0.463 in 2012 and 0.540 in 2014. The overall fluctuation of HDI value of SAARC countries is vividly presented in Fig.1, above. 


\section{CONCLUSION}

The generated trends showed that there is a trend of increase in the Human Development Index in all the SAARC countries. After analyzing the data, it can be concluded that the difference between the SAARC countries' HDI is because of the much higher differences in the education index and adult literacy rate. However, HDI in SAARC countries is not as high as it could be. The study reveals that SAARC countries have been showing continuous progress in the three different years of study. Sri-Lanka, Maldives, India, Bhutan, Bangladesh, Nepal, Pakistan and Afghanistan rank respectively in the order of HDI from the highest to the lowest in SAARC where Sri-Lanka belongs to the group of countries with 'high human development index', Maldives, India, Bhutan and Bangladesh belong to 'medium human development index' and Nepal, Pakistan and Afghanistan belong to 'low human development index'.

Human development index is the mirror of the country for its overall social and economic performance. With the combined assembly of the individual country's information, total HDI configuration reflects the global status. It also provides the valuable insights for economic development of the country. Rise and fall in HDI can be treated as the indicator of developmental status of the country. Formulation of policies, their implementation, shaping the national and international targets etc are firmly guided by the HDI of the country and its sound comparison with neighboring states, regions and continents. Thus, collective effort to rectify common problem of the region, continent and the globe is mandatory. The nation alone is not capable enough to combat vulnerabilities and build resilience to sustain human progress in this era.

\section{REFERENCES}

UNDP (2010). Human Development Report 2010, New York:. United Nations Development Program (UNDP) http//hdr.undp.org/en/media/HDR_2010_EN_complete.pdf. Accessed on Aug. 12, 2014.

UNDP (2012). Human Development Report 2012. New York: UNDP. http//hdr.undp.org/en/media/HDR_2012_EN_complete.pdf. Accessed on Aug. 12, 2014.

UNDP (2014). Human Development Report 2014. New York: UNDP. http//hdr.undp.org/en/media/HDR_2014_EN_complete.pdf. Accessed on Aug. 12, 2014. 